\title{
A Tentative Analytical Approach to the Determination of Interlibrary Loan Network Effectiveness
}

\begin{abstract}
Because increasing amounts of public resources are being committed to network development, analytical frameworks within which to conduct empirically based studies are needed to facilitate scientific assessments of network effectiveness. A tentative approach is outlined wherein comparative unit-system measurements are employed. The data utilized are those resulting from a state interlibrary loan network study, but the resultant descriptive framework is applicable to networks with similar unit-system relationships.
\end{abstract}

I es are being committed to network development so that rational decision-making with respect to the application of these resources must ultimately come to depend on scientific assessments of existing networks. Although there are numerous interlibrary loan networks in the United States, there are few empirically based general statements-descriptive, explanatory, or evaluativerelative to their effectiveness (i.e., the degree to which they realize their goals, normally measured in terms of output). This paucity of generalizations may be, in part, a function of the absence of suitable analytical frameworks within which to conduct empirical studies.

The tentative analytical approach to the determination of interlibrary loan

Mr. Warner is the library planner with the Baltimore Regional Planning Council, Baltimore, Maryland.

The writer is indebted to Edwin E. Olson, associate professor, School of Library and Information Services, University of Maryland, for his critical review of an earlier draft of this paper. network effectiveness outlined herein, and its application in one statewide study, yield an essentially comparative descriptive-analytical framework.

At the outset of 1969, the present writer was engaged as principal investigator to analyze Maryland Interlibrary Loan Network transactions in an effort to assess the network's effectiveness. Some months later the study culminated in a report issued by the appropriate state unit. ${ }^{1}$

At the time of the study, the Maryland Interlibrary Loan Network consisted of twenty-three county libraries, a regional subsystem of seven county libraries, several small college and special libraries, a primary library, and a secondary library. The Enoch Pratt Free Library in Baltimore has functioned as the network's transaction clearinghouse as well as its primary lending library. Generally, the county, college, and special libraries initiate the requests into the network by teletyping them directly to Pratt. As an exception to this, however, the county libraries comprising the Eastern Shore Area Arrangement submit their requests to the Area Li- 
brary. Unfilled requests are then forwarded to Pratt. Only the Pratt Library may send still unfilled requests on to the McKeldin Library at the University of Maryland in College Park, the secondary or "back-up" library (see Figure 1).

The data base utilized herein de- rives from a random sample of loan transactions (evidenced by the teletype records of loan requests) introduced into the network, and the responses thereto through the twenty-eighth day after receipt. The sample consists of 1,148 requests received by the Pratt Library

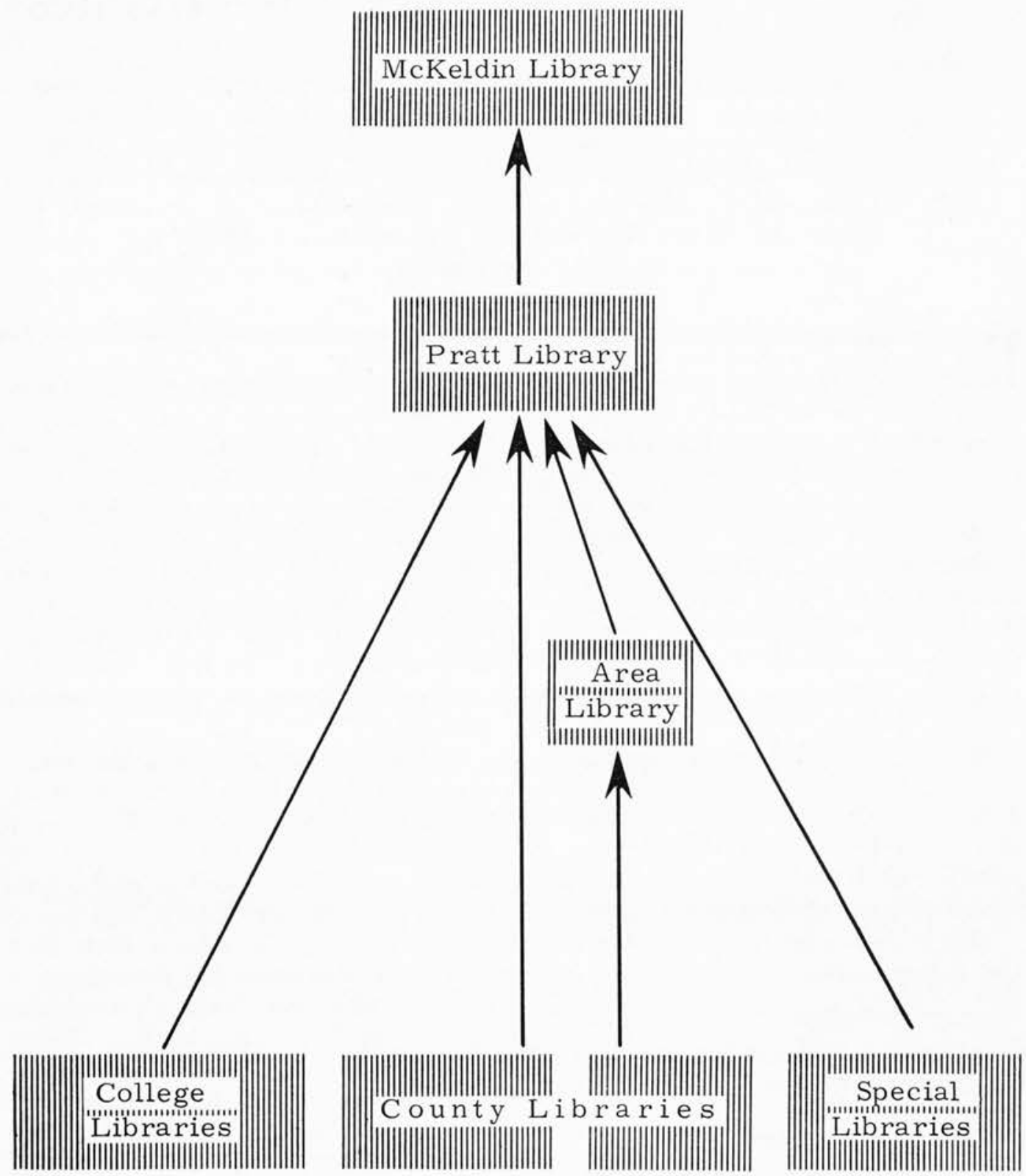

Figure 1

Maryland Interlibrary Loan Network, Showing Flow of Requests 
(including those received by the Eastern Shore Area Library, recorded simultaneously by the Pratt Library and the Area Library TWX terminals) during a five-day period in January $1969 .{ }^{2}$ An overwhelming majority of the requests both originated with the twentythree county libraries (93.1 percent) and were requests for monographic materials ( 87.0 percent). The units of analysis, then, are loan requests, whereas output consists of the filled requests.

Analysis of the 1,148 requests in the Maryland Study-using a definition of "requests filled" which allowed two weeks for the disposition of the requests -revealed, in total system terms, that 677 of the requests were filled; that is, network effectiveness could be characterized as 59.0 percent (system output over system input). However, in a system with unit relationships approximating those found in the Maryland network, requests are subjected to a sequential screening or eliminative process which must be accounted for before attempting to further describe or to explain and evaluate effectiveness (see Figure 1). In the Maryland case, therefore, it was necessary to measure the relative contributions of the Area, Pratt, and McKeldin libraries as component units in the system.

Of the 1,148 requests introduced into the network (system input), 110 (9.6 percent) were filled by the Eastern Shore Area Library prior to being proc- essed by the Pratt Library, so that 1,038 still active requests remained. Of these, 492 (42.9 percent) of the original 1,148 requests introduced into the network were filled by the Pratt Library. ${ }^{3}$ In turn, the Pratt Library elected to forward 149 still active requests to the McKeldin Library wherein 75 (6.5 percent) of the original 1,148 requests introduced into the network were filled. Using system input as a base, total system effectiveness of 59.0 percent can be seen as the sum of the unit outputs (see Table 1).

On the other hand, of the 232 requests in the sample actually received by the Area Library (unit input), 110 (47.4 percent) were filled by the Area Library. Of the 1,038 requests actually received by the Pratt Library, 492 (47.4 percent) were filled by the Pratt Library; and of the 149 requests actually received by the McKeldin Library, 75 (50.3 percent) were filled by the McKeldin Library (see Table 1).

In systems approximating the Maryland network, then, meaningful assessment must comprehend unit contributions to the system in terms of both the input to each unit as well as the input to the system. That is, unit output should be measured in unit input terms (i.e., unit effectiveness) as well as system input terms, whereas system output can be measured only in system input terms (i.e., system effectiveness).

In the Maryland case, network effec-

TABLE 1

Unit Output Showing Requests Filled as a Proportion OF THOSE INTRODUCED INTO THE SYSTEM AND AS A Proportion of those Actually Received BY THE UNITS

\begin{tabular}{|c|c|c|c|c|c|c|c|}
\hline & Area & & Pratt & & McKeldin & & \\
\hline Introduced & 110 & & 492 & & 75 & & \\
\hline \multirow[t]{2}{*}{ Received } & $\begin{array}{r}1,148 \\
110\end{array}$ & (9.6\%) & $\begin{array}{r}1,148 \\
492\end{array}$ & (42.9\%) & $\begin{array}{r}1,148 \\
75\end{array}$ & $(6.5 \%)$ & Total $=59.0 \%$ \\
\hline & 232 & $(47.4 \%)$ & 1,038 & $(47.4 \%)$ & 149 & $(50.3 \%)$ & Mean $=48.4 \%$ \\
\hline
\end{tabular}


tiveness was shown to be greater than either the mean effectiveness of the component units or the effectiveness of any one of the component units. On its face, of course, a finding such as this would lend support to the existence and maintenance of a system of the type assessed.

The screening or eliminative aspect of this type of system may be illustrated in another manner. By considering the requests first submitted to the Area Library and those not first submitted to the Area Library as two subsamples, it can be seen that the success rate of the Area Library subsample, when weighted by that subsample's proportion of total requests, has a disproportionately positive effect on the total system's effectiveness. That is, the requests first routed through the Area Library comprise only 20.2 percent of those introduced into the system, but 77.1 percent of them were filled, whereas the requests which were not routed through the Area Library first comprise 79.8 percent of the requests introduced into the system, of which only 54.4 percent were filled (see Table 2). When the success rate of the Area Library subsample is weighted by the proportion of the total requests that the subsample comprises and is then taken as a proportion of the system's success rate, the resultant contribution of that subsample to network effectiveness is revealed to be 26.4 percent and thereby greater than its ab- solute participation ( 20.2 percent of the requests).

That the Maryland Interlibrary Loan Network has been characterized herein as 59.0 percent effective does not necessarily mean that an output (requests filled) of 100 percent is to be taken as an ideal goal. One authority has suggested, in fact, that "the goal model may not supply the best possible frame of reference for effectiveness" in that "it compares the ideal with the real, as a result of which most levels of performance look alike-quite low."4

The percentage or proportional characterization may however be conveniently utilized for intrasystem or internal analytical purposes and has been so used herein. That is, any total system effectiveness measurement must somehow be comprised of unit contributions (although not, as has been shown, necessarily on a sum-of-the-parts basis), so that to internally analyze a system's effectiveness, it is necessary only that $a$ quantitative total system effectiveness statement be made against which unit contributions can be gauged. Moreover, if a total system's effectiveness at any given time is to be measured against that system's effectiveness at another point in time, $a$ quantitative total system effectiveness statement will again suffice in that each effectiveness measurement, if comparably derived, will become a relative measurement in a time series. ${ }^{5}$

TABLE 2

Unit and System Output, Showing Area Library Subsample, Library Subsample, and Network Effectrveness

\begin{tabular}{|c|c|c|c|c|c|c|c|c|}
\hline & Area & & Pratt & & McKeldin & & & \\
\hline Area & $\frac{110}{232}$ & $(47.4 \%)$ & $\frac{61}{232}$ & $(26.3 \%)$ & $\frac{8}{232}$ & $(3.4 \%)$ & $\frac{179}{232}$ & $(77.1 \%)$ \\
\hline Nonarea & - & - & $\frac{431}{916}$ & $(47.1 \%)$ & $\begin{array}{r}67 \\
916\end{array}$ & $(7.2 \%)$ & $\frac{498}{916}$ & $(54.4 \%)$ \\
\hline Total & $\frac{110}{1,148}$ & $(9.6 \%)$ & $\frac{492}{1,143}$ & (42.9\%) & $\frac{75}{1,145}$ & $(6.5 \%)$ & $\frac{677}{1,148}$ & (59.0\%) \\
\hline
\end{tabular}


There has emerged, then, an elementary descriptive-analytical framework reflecting comparative unit and system input and output and within which further analysis of effectiveness might proceed. That is, additional statements describing, as well as explaining and evaluating effectiveness can be couched in terms of the comparative unit-system framework herein developed.

\section{REFERENCES}

1. See Edward S. Warner, "Maryland Interlibrary Loan Network Loan Requests: System and Units Analysis" (Baltimore: Maryland State Department of Education, Division of Library Development and Services, 1969).
2. The original study also utilized a smaller sample consisting of 612 requests received by the Pratt Library during a two-day period in February 1969.

3. Includes, under the two-week definition referred to above, requests filled as a result of placing reserves on Pratt Library materials, an option which the Pratt Library may (and does) exercise. Forty requests were in this way filled in the sample and are included with the Pratt Library figures though they materialized after sending 149 still active requests on to the McKeldin Library.

4. Amitai Etzioni, "Two Approaches to Organizational Analysis: A Critique and a Suggestion," Administrative Science Quarterly 5:260 (Sept. 1969).

5. Intersystem or external comparisons will also produce relative effectiveness measurements, assuming comparably derived measurements. 